\title{
PRINCÍPIOS CONSTITUCIONAIS NO PROCESSO DE DOSIMETRIA DE PENA
}

\author{
CONSTITUTIONAL PRINCIPLES IN THE PEN DOSIMETRY PROCESS
}

\author{
Turíbio Marques Gonçalves Júnior ${ }^{1}$ \\ Bernardo Ricciardi dos Santos Brum ${ }^{2}$ \\ João Pedro Andrades Salles Soares ${ }^{3}$ \\ Pedro Antônio Lorentz Martins ${ }^{4}$
}

\begin{abstract}
RESUMO: O procedimento dosimétrico da pena no processo penal brasileiro é formado por três fases distintas, que resultam numa pena definitiva, devendo esta ser justa e proporcional, com fim de reprovar e prevenir o delito. Nesse contexto, faz-se curial apontar os princípios constitucionais que norteiam o processo penal, sobretudo quanto à fixação da pena, quais sejam a legalidade, dignidade da pessoa humana, proporcionalidade e a individualização da pena. Nesse sentido, a presente pesquisa busca entender o enfoque dos princípios constitucionais que regem o processo dosimétrico da pena no processo penal brasileiro. Para tanto, o presente estudo é divido em dois grandes capítulos. No primeiro, tratar-se-á acerca da evolução do processo dosimétrico no processo penal brasileiro. $\mathrm{Na}$ segunda metade, será realizada a explanação dos princípios que norteiam o processo penal, sobretudo quanto à fixação da pena.
\end{abstract}

Palavras-chave: Dosimetria da pena. Princípio da individualização da pena. Processo penal brasileiro.

ABSTRACT: The dosimetric procedure of the penalty in the Brazilian criminal process is formed by three distinct phases, which result in a definitive penalty, which must be fair and proportional, in order to reprove and prevent the crime. In this context, it is curial to point out the constitutional principles that guide the criminal process, especially regarding the setting of the penalty, which are the legality, human dignity, proportionality and the individualization of the penalty. In this sense, the present research seeks to understand the focus of the constitutional principles that govern the dosimetric process of punishment in the Brazilian criminal process. To this end, the present study is divided into two major chapters. In the first, it will deal with the evolution of the dosimetric process in the Brazilian criminal process. In the second half, there will be an explanation of the principles that guide the criminal process, especially regarding the setting of the sentence.

\footnotetext{
${ }^{1}$ Graduado em Relações Internacionais pela Universidade de Santa Cruz do Sul (UNISC). Pós-graduado em Gestão de Segurança Pública pela UniBF. Policial Penal da SEAPEN/RS. E-mail: turibiomg@gmail.com.

${ }^{2}$ Graduado em Educação Física pela Universidade da Região da Campanha de Alegrete (URCAMP). PósGraduado em Gestão de Segurança pública pela UniBF. Policial Penal da SEAPEN/RS.

3 Graduado em Direito pela Faculdade de Direito de Santa Maria (FADISMA). Pós-graduado em Gestão Penitenciária pela Faveni. Pós-graduando em Gestão em Segurança Pública pela Intervale. Pós-graduando em Direito Ambiental pela Intervale. Pós-graduando em Direito Ambiental e Econômico pela Intervale. Pósgraduando em Direito Agrário e Ambiental pela Verbo Jurídico. Policial Penal da SEAPEN/RS.

${ }^{4}$ Graduado em Direito pela Faculdade de Direito de Santa Maria (FADISMA). Pós-Graduado em Inteligência Policial pela Faveni. Policial Penal da SEAPEN/RS.
} 
Keywords: Feather dosimetry. Principle of individualization of the penalty. Brazilian criminal proceedings.

\section{INTRODUÇÃO}

Desde o século XVII busca-se a conscientização da importância e a finalidade da pena, atribuindo a essa as características de prevenção e repressão. A inflição da pena está diretamente ligada ao conjunto fático do delito, assim como, voltado exclusivamente ao acusado, de forma ser necessário que todos os vetores devam incidir na dosimetria da pena, a fim de que se tenha um julgamento justo e adequado, sem excessos, tanto positivo quanto negativamente. Assim, o processo dosimétrico carece de maior atenção, em razão de sua fundamental importância na inflição da pena.

$\mathrm{Na}$ atual conjuntura do sistema punitivo, a pena não atinge os fins a que foi idealizada, violando diariamente os direitos fundamentais daqueles que a se sujeitam. A aplicação da pena devese pautar e primar, no mínimo, pela legalidade e proporcionalidade da pena, evitando a extensão da culpabilidade injusta. Entretanto, verifica-se que, atualmente, os tribunais brasileiros deixam de aplicar penas justas aos acusados, invocando o teor da Súmula n.o 23I, do Superior Tribunal de Justiça, a qual prevê que "a incidência da circunstância atenuante não pode conduzir à redução da pena abaixo do mínimo legal". O texto em análise impossibilita ao magistrado reduzir a pena provisória, na segunda fase, aquém do previsto abstratamente em lei quando presente circunstância atenuante.

Nesse sentido, a presente pesquisa estudará o processo dosimétrico sob o enfoque dos princípios constitucionais que regem o processo dosimétrico da pena no processo penal brasileiro.

\section{A evolução do processo de dosimetria da pena}

Os primeiros passos do processo dosimétrico foram marcados pela arbitrariedade, sobretudo pela presença da figura de um magistrado que possuía ampla autonomia no julgamento, fixando penas sem quaisquer balizas (MIRABETE, 2006, p. 297). Nesse ínterim, era cediço a existência de ilegalidades e parcialidades, prejudicando a classe mais fraca (GARCIA,I956, p. 46I-463).

Com os reflexos dos ideais iluministas desembarcando no Brasil, o juiz que antes detinha o poder, agora, limitava-se a dizer a lei. A garantia da individualização da pena, no que the concerne, deu-se paulatinamente, ante a consolidação do Código Criminal do Império apenas em I830, revogando as disposições aterrorizantes das Ordenanças Filipinas (BOSCHI, 2014, p. 146). Consoante o teor do Código em apreço, sobretudo a segunda parte, o juiz, ao individualizar a pena, estaria adstrito a graus de reprovabilidade - mínimo, médio e máximo - previamente estabelecidos e sem qualquer margem de liberdade, classificados conforme a incidência de agravantes ou 
atenuantes no delito praticado, destacando-se que, em havendo dúvida quanto ao grau, este seria fixado no médio, consoante art. 20 (BOSCHI, 2014, p. 147).

Ora, na vigência do Código Imperial a figura do magistrado restringia-se a ditar o estabelecido na legislação, identificando a ocorrência do fato e o respectivo grau de desaprovação da conduta, aplicando a sanção correlata. Vislumbra-se aqui a figura do juiz idêntica àquela empregada no período napoleônico - bouche de la loi, boca da lei -, no qual estes possuíam atuação mecânica, haja vista a ausência de liberdade, sendo apenas mero intermediário entre o fato e a lei (GOMES, 2002).

Consoante as palavras de Pedro Vergara (1948, p. 249):

[...] não podia fazer um balanço geral de todos os elementos que concorriam na ação criminosa, para deduzir a imputação e calcular a responsabilidade, ou fosse a quantidade da pena; não estava no seu poder fundir esses elementos e extrair da sua mistura a fórmula complexiva da punibilidade, em que se harmonizassem as exigências da repressão e da intimidação, com as necessidades políticos da individualização das sanções. (VERGARA, 1948, p. 249)

Na sequência, aviou o Código Penal de I89o, acrescendo dois graus de reprovabilidade a ser considerado pelo juiz: submáximo e sub-médio, contudo, não concedendo a esta liberdade para julgar (MASSUD, 2009, p. 138). Não obstante, em 1940, na vigência do Estado Novo, aportou o Código Penal, ainda vigente, Decreto-Lei n.o $2.848 /$ 1940, trazendo no seu bojo a abolição dos graus de reprovabilidade e "longe das fórmulas aritméticas, [...] ampliou extraordinariamente o arbítrio judicial, disponibilizando ao magistrado um autêntico roteiro de investigação das circunstâncias fáticas do crime e da pessoa do réu [...]” (BOSCHI, 20I4, p. I48).

Ora, a partir do novo texto legal tem-se "o exercício verdadeiro da tarefa de individualizar a pena, cuja fixação, agora, prendia-se tão somente aos limites da moldura dos tipos penais, ou seja, aos marcos mínimo e máximo da reprimenda" (BOSCHI, 2014, p. I48). Nesse diapasão, a figura do juiz ganha liberdade ao dosar a pena, entretanto, circunscrito pela legislação penal, de modo a que o arbítrio delegado pelo legislador seja relativo e ponderado. Contudo, pairava uma problemática acerca do sistema de aplicação da pena: se empregava o sistema bifásico ou trifásico (BOSCHI, 20I4, p. 148).

Na operação bifásica, proposta por Roberto Lyra, o cálculo da pena levava em consideração as circunstâncias judiciais, dispostas no art. 42 da antiga redação, e as circunstâncias legais, agravantes e atenuantes, a fim de se determinar a pena-base. A partir dessa pena, incidiria, num 
derradeiro momento, as causas de aumento ou diminuição da pena, moldando a pena definitiva (SHECAIRA, 1995, p. 174-175).

Destaca-se que na adoção do sistema bifásico o réu restaria prejudicado em seu direito a recorrer da própria decisão, como pela própria ciência da mesma, uma vez que, pela análise das circunstâncias judiciais e legais num mesmo momento, torna-se desconhecido o quantum somado ou subtraído na pena-base pelas agravantes e atenuantes. Assim, o processo trifásico apresentar-se-ia como mais benéfico ao réu, sobretudo quanto a clareza na aplicação da punição (DUARTE, 1942, p. 216).

De outro lado, o sistema trifásico, tutelado por Nelson Hungria, à época da vigência do Código Penal em questão, fixava a pena-base sopesando as circunstâncias judiciais, hoje dispostas no art. 59 do Código Penal. Após, analisavam-se as circunstâncias agravantes e atenuantes, e, por fim, as causas de aumento ou diminuição da pena (BOSCHI, 20I4, p. I5I).

Ora, a adoção do sistema trifásico garante ao réu o pleno exercício da ampla defesa, não garantido no bifásico, mormente pela oportunidade dado ao mesmo de poder vislumbrar a pena aplicada no processo de forma clara e separada. Ademais, o sistema em análise favorece ao condenado, visto que é um modelo de aplicação de pena esclarecido, clarificado, oportunizando ao mesmo as condições e circunstâncias que culminarem na produção da pena (SHECAIRA, 2002. p. 275).

Após a discussão acerca do procedimento a ser empregado atravessar a vigência do Estatuto Penal de 1940, o deslinde da celeuma posta deu-se através da Lei nำ 7.209/84, no qual houve a reforma da Parte Geral do Código em tela, oportunidade em que se pacificou a utilização do sistema trifásico como método para individualização da pena, por meio expresso disposto no art. 68 , in verbis, "a penabase será fixada atendendo-se ao critério do art. 59 deste Código; em seguida serão consideradas as circunstâncias atenuantes e agravantes; por último, as causas de diminuição e de aumento" (BOSCHI, 2014, p. 152-153).

Em suma, o sistema trifásico, protagonizado por Hungria, desenvolve-se pela aplicação de três fases diferentes, definindo-se: (i) a pena-base, com a verificação das circunstâncias judiciais do art. 59, CPB; (ii) a pena provisória, levando-se em conta a incidência de agravantes ou atenuantes, e (iii) a pena definitiva, tem-se a exacerbação ou diminuição da pena, com a utilização das causas de aumento ou diminuição da pena (SHECAIRA, 1995, p. 174-175).

Em que pese a doutrina considere que as circunstâncias legais sejam obrigatórias, consoante já ressaltado, há a excepcionalidade da Súmula 23i do STJ. Conforme preconiza a súmula em 
comento, "a incidência da circunstância atenuante não pode conduzir à redução da pena abaixo do mínimo legal”.

Dessa forma, pela análise latu sensu do sumulado pelo STJ denota-se que o entendimento do Egrégio é que a pena somente pode ultrapassar os limites, aquém ou além, estabelecidos na lei em duas oportunidades: a uma, se a pena-base for fixada acima do mínimo legal e, na segunda fase, incidir circunstância atenuante; e a duas, se, na terceira fase, ocorrerem causas de aumento ou diminuição de pena.

\section{Princípios constitucionais de aplicação da pena}

A Carta Cidadã de 1988, mais conhecida como Constituição Federal, inovou o cenário social brasileiro, sobretudo pelas inúmeras garantias e tutelas pró-cidadão. Nesse ínterim, registar-se os princípios enquadrados no art. 5, da Lei Maior, sobretudo aqueles que norteiam a aplicação do processo penal no Brasil.

Inicialmente, não se pode olvidar a soberania do princípio da legalidade sobre os demais, sobretudo em razão de vivermos numa república democrática de direitos, bem como que somente a lei - e não outra fonte - traduzirá o que é crime.

No ordenamento jurídico brasileiro se verifica o referido princípio disposto no artigo 5.. da Constituição Federal, inciso XXXIX, assim como, na legislação infraconstitucional, no artigo ı. ${ }^{\circ}$ do atual Estatuto Penal, in verbis, "não há crime sem lei anterior que o defina, nem pena sem prévia cominação legal”. Frisa-se, igualmente, a mesma disposição na Convenção Americana de Direitos Humanos, no bojo do artigo 9.ำ, nullum crimen, nulla poena sine praevia lege (ORGANIZAÇÃO DOS ESTADOS AMERICANOS, 1969).

Outrossim, registar-se que o princípio da legalidade guarda relação com a segurança jurídica, sobretudo para proteger os cidadãos do arbítrio do Estado em punições sem base legal expressa. Ainda, exige correlação entre o ato praticado e descrição preestabelecida na legislação, tudo para dar maior proteção ao cidadão, principalmente a não utilização da analogia in malam partem (ESTEFAM, 2012, p. 123).

De outra banda, destaca-se o princípio da dignidade da pessoa humana, positivado no artigo ı.o, inciso III, da Constituição Federal, classificado como um dos fundamentos da República Federativa do Brasil, além de sua previsão no preâmbulo da Declaração Universal dos Direitos do Homem (ORGANIZAÇÃO DAS NAÇÕES UNIDAS, 1948) e na Convenção Americana de Direitos Humanos (ORGANIZAÇÃO DOS ESTADOS AMERICANOS, 1969). Em que pese não se tratar de um princípio propriamente penal, é utilizado como referência para aplicação e interpretação de todas as normas jurídicas. 
Em suma, a sua conceituação do princípio da dignidade da pessoa humana é muito divergida, mas nas palavras de Alexandre de Moraes se perfaz como a proteção ao direito individual em relação ao Estado, bem como o respeito ao tratamento igualitário com os demais indivíduos, de modo a que se estabeleça uma reciprocidade no respeito à dignidade (MORAES, 200o, p. 60-6I).

Ademais, frisa-se que o princípio da dignidade da pessoa humana na aplicação da pena muito se relaciona com o princípio da humanidade, sobretudo consoante o entendimento doutrinário, através das duas ramificações a partir do princípio em tela: a vedação de responsabilização de conduta inofensiva e a proibição de inflição de penas cruéis, degradantes e vexatórias (ESTEFAM, 2012, p. 131).

De outra baila, merece atenção o princípio da individualização da pena, esculpido no art. $5^{\circ}$, inciso XLVI, da Lei Maior, de 1988, o qual aponta que as inflições deverão atentar para as particularidades de cada indivíduo ao caso concreto, a fim de que cada acusado tenha uma pena individualizada (BOSSI, FANTECELLE, 2015), ou seja, "retribuir o mal concreto do crime, com o mal concreto da pena, na concreta personalidade do criminoso" (LUIZI, 2003, p. 52).

Tal princípio é o produto de três etapas distintas, iniciando pelo legislador, o qual é vedado o estabelecimento de delitos que limitem o aplicador da pena à análise do caso concreto, com a apuração das circunstâncias pessoais do autor que se liguem ao fato e a natureza do crime. $\mathrm{Na}$ sequência, tem-se a individualização judicial, em que se tem como processo de aplicação da pena o sistema trifásico, sendo defeso ao magistrado a inflição de sanção padronizada. Por derradeiro, há a individualização executiva, em que se colima uma execução da pena voltada à ressocialização (ESTEFAM, 2012, p. 13I).

Conforme Boschi (2014, p. 53) e pelo acima exposto, com a individualização da pena buscase a singularização e especificação da pena no caso concreto, sobretudo para evitar um procedimento padronizado por parte do Estado. Ainda, sobre o assunto, verifica-se que após a Reforma Penal, de 1984, como já descrito, engessou-se o sistema trifásico de aplicação da pena, possibilitando ao acusado ter ciência sobre os fatores que foram agregados à pena, tanto na majoração, quanto na minoração, sobretudo de modo a proporcionar o direito ao duplo grau de jurisdição (FORATO, 20II).

Assim sendo, com a Reforma Penal de 1984, deu-se fim à cizânia posta quanto ao sistema de aplicação da pena, elegendo-se o método trifásico. No mesmo cenário, verificou-se a utilização dos princípios constitucionais que enlaçam o contexto de inflição da pena, sobretudo a garantir uma pena justa, proporcional e legal. 


\section{Considerações finais}

Muito se discorreu no Brasil, com o advento do Código Penal de 1940, acerca do sistema a ser utilizado quando da aplicação da pena. A controvérsia era protagonizada por Roberto Lyra e Nelson Hungria, onde aquele conceituava e defendia o sistema bifásico, sendo este, por seu turno, advogado do sistema trifásico. Com o aporte da Reforma Penal de 1984, edição da Lei n.o 7.209/84, colocou-se termo à cizânia posta, elegendo o sistema trifásico. Assim, a aplicação da pena passou a obedecer a três fases distintas: em primeiro lugar, aplicar-se-ia a pena-base, por meio da análise das circunstâncias judiciais do art. 59, do Código Penal; em segundo momento, serão avaliadas as circunstâncias atenuantes e as agravantes, e por fim, consideradas as causas de aumento e diminuição da pena, caso necessário.

Inobstante a elaboração da Súmula 231 se dar pela Corte Superior, suscitaram dúvidas quanto a sua constitucionalidade, sobretudo frente aos princípios constitucionais que norteiam o processo dosimétrico, quais sejam, a legalidade, a individualização da pena e a dignidade da pessoa humana. De um lado, a jurisprudência sustenta a constitucionalidade ante a ausência de atribuição valorativa pelo legislador, da forma como é disponibilizado às causas de aumento e diminuição.

De outra baila, a doutrina majoritária advoga pela inconstitucionalidade, haja vista a ausência de previsão legal que indique a vedação da redução da pena provisória aquém do mínimo legal, bem como, pela grave violação aos direitos e garantias fundamentais do acusado, mormente de se conquistar uma pena justa e proporcional.

Inicialmente, verificou-se o contexto no qual foi elaborada a Súmula 23I do STJ, sobretudo os precedentes que deflagraram a respectiva súmula. Ao todo foram sete precedentes, que variaram desde 1991 até 1997 , que deram ensejo a vedação da redução da pena provisória aquém do mínimo legal. Conforme se percebe, inclusive pela evolução do processo dosimétrico, o Código Penal vigente foi publicado em 1940, sendo que a sua redação original não esclarecia o método de aplicação da pena, contudo, se sobressaía o bifásico.

O referido sistema dosava a pena em duas fases, na primeira eram analisadas as circunstâncias judiciais e legais e na segunda fase as causas de aumento e diminuição, sendo pacífico o entendimento que a pena somente poderia ultrapassar os limites abstratamente previstos na segunda fase. Contudo, com a Reforma Penal de 1984, o sistema trifásico prevaleceu no ordenamento jurídico brasileiro. Não obstante, poucos anos depois, o Superior Tribunal de Justiça, ainda vinculado às características do sistema bifásico, e a respectiva vedação da redução da pena em razão da incidência de circunstância atenuante, editou a súmula em comento no mesmo sentido. 
Dessa forma, enquadrou-se o teor da súmula aos ditames constitucionais, a fim de constatar a sua (in)constitucionalidade. Ora, as leis devem se basear pela disposição da Constituição Federal, sendo que em matéria penal a interpretação ainda é mais rígida.

Pela presente pesquisa, verificou-se a não observância de preceitos básicos dispostos na Carta Constitucional, princípio da legalidade, da individualização da pena e dignidade da pessoa humana, encontrando-se o teor da Súmula 23I do STJ em plena desconformidade. Ora, o teor da Súmula 23I do STJ apresenta vedação da redução da pena provisória aquém do mínimo legal, entretanto, não há determinação legal nesse sentido, e sendo este entendimento limitador de direitos e garantias, verifica-se grave violação à dignidade do acusado, mormente a de ser julgado a uma pena justa e proporcional.

Ademais, menciona-se que a legislação infraconstitucional, de forma imperativa, aponta em sentido contrário da súmula, descrevendo que as atenuantes "são circunstâncias que sempre atenuam a pena”, não abrindo margem a exceções. Nesse mesmo sentido acerca da legislação infraconstitucional, cita-se que o Superior Tribunal de Justiça ao elaborar a súmula em tela utilizouse do instituto da analogia, com base na antiga redação do artigo 42, parágrafo único, do Código Penal de 1940. Não obstante, é cediço que a analogia, na seara penal, somente será utilizada quando beneficiar o réu, o que não é o caso da presente súmula.

Ainda, destaca-se que o emprego do sistema trifásico é uma garantia para que o acusado possa ter acesso às variáveis que conduziram a sua pena no patamar fixado pelo magistrado, inclusive garantindo o acesso ao duplo grau de jurisdição. Dessa forma, a pena, quando não reduzida na segunda parte do procedimento dosimétrico, mesmo havendo atenuante presente no caso concreto, não condiz com o crime praticado, não atingindo sua finalidade desde a sua fixação. Conclui-se, assim, que o teor da Súmula 23i do Superior Tribunal de Justiça afronta a Constituição Federal, sobretudo quanto à dignidade da pessoa humana, à individualização da pena, à legalidade e à igualdade.

\section{Referências bibliográficas}

BOSCHI, José Antonio Paganella. Das Penas e seus Critérios de Aplicação. 7 ed. atual. Porto Alegre: Livraria do Advogado Editora, 2014.

BOSSI. Letícia e FANTECELLE, Gylliard. Súmula 23I do STJ e a sua (in)aplicabilidade na dosimetria penal. Disponível em: $\langle$ http://www.fenord.edu.br/revistaaguia/revista2015/textos/artigoo9.pdf $\rangle$. Acesso em: or dez. 2016.

BRASIL. Código Penal de 1940. Disponível em: 〈http://www.planalto.gov.br/ccivil_03/decretolei/Del2848compilado.htm>. Acesso em: 13 out. 2016. 
. Constituição da República Federativa do Brasil de 1988. Disponível em: 〈https://www.planalto.gov.br/ccivil_03/constituicao/constituicao.htm〉. Acesso em: Io out. 2016.

DUARTE, José. Aplicação da pena - Pena base - Inteligência do art. 5o. São Paulo: Revista Justitia, ano 1942 , v. 4.

ESTEFAM, André. Direito penal, r: parte geral/André Estefam. - 2. Ed - São Paulo: Saraiva, 2012.

GARCIA, Basileu. Instituições de direito penal. 4. ed. São Paulo: Max Limonad, I975. v. I, t. 2. 1956.

GARCIA, Dionísio. As circunstâncias atenuantes e agravantes continuam adstritas aos limites punitivos do tipo. Disponível em: <http://bdjur.stj.jus.br/dspace/handle/2011/26907〉. Acesso em: o8 nov. 2016.

GOMES, Luiz Flávio. Atenuantes podem reduzir pena abaixo do mínimo legal. Disponível em: $\langle$ http://www.conjur.com.br/2002-set-29/sumula_stj_conflito_direito_vigente〉. Acesso em I4 nov. 2016

Reformas penais (XV): Pena abaixo do mínimo legal. Mundo Jurídico. Disponível em: 〈http:/ http://www.buscalegis.ufsc.br/revistas/files/anexos/II704-II704-I-PB.htm〉. Acesso em: 04 dez. 2016.

LUIZI, Luis. Os princípios constitucionais penais. 2. ed. Porto Alegre: Sergio Antonio Fabris Editor 2003.

MASSUD, Leonardo. Da pena e sua fixação. São Paulo: DPJ Editora, 2009.

MIRABETE, Julio Fabbrini; FABBRINI, Renato. Manual de Direito Penal - Parte Geral. 26. ed. São Paulo: Ed. Atlas, 2oro.

MORAES, Alexandre de. Direitos Humanos Fundamentais. $3^{\underline{a}}$ edição, São Paulo, Atlas, 2000.

SHECAIRA, Sérgio Salomão; CORRÊA JUNIOR. Alceu. Pena e constituição: aspectos relevantes para sua aplicação e execução. São Paulo: Editora Revista dos Tribunais, 1995.

VERGARA, Pedro. Das penas principais e sua aplicação. Imprenta: Rio de Janeiro, Boffoni, 1948. 